\title{
Infecção por Helicobacter pylori e câncer gástrico: freqüência de cepas patogênicas cagA e vacA em pacientes com câncer gástrico
}

\author{
Helicobacter pylori and gastric cancer: distribution of cagA and vacA genotypes in patients \\ with gastric carcinoma
}

Cristiane Melissa Thomazini'; Nídia Alice Pinheiro²; Maria Inês Pardini²; Luís Eduardo Naresse ${ }^{3}$; Maria Aparecida Marchesan Rodrigues

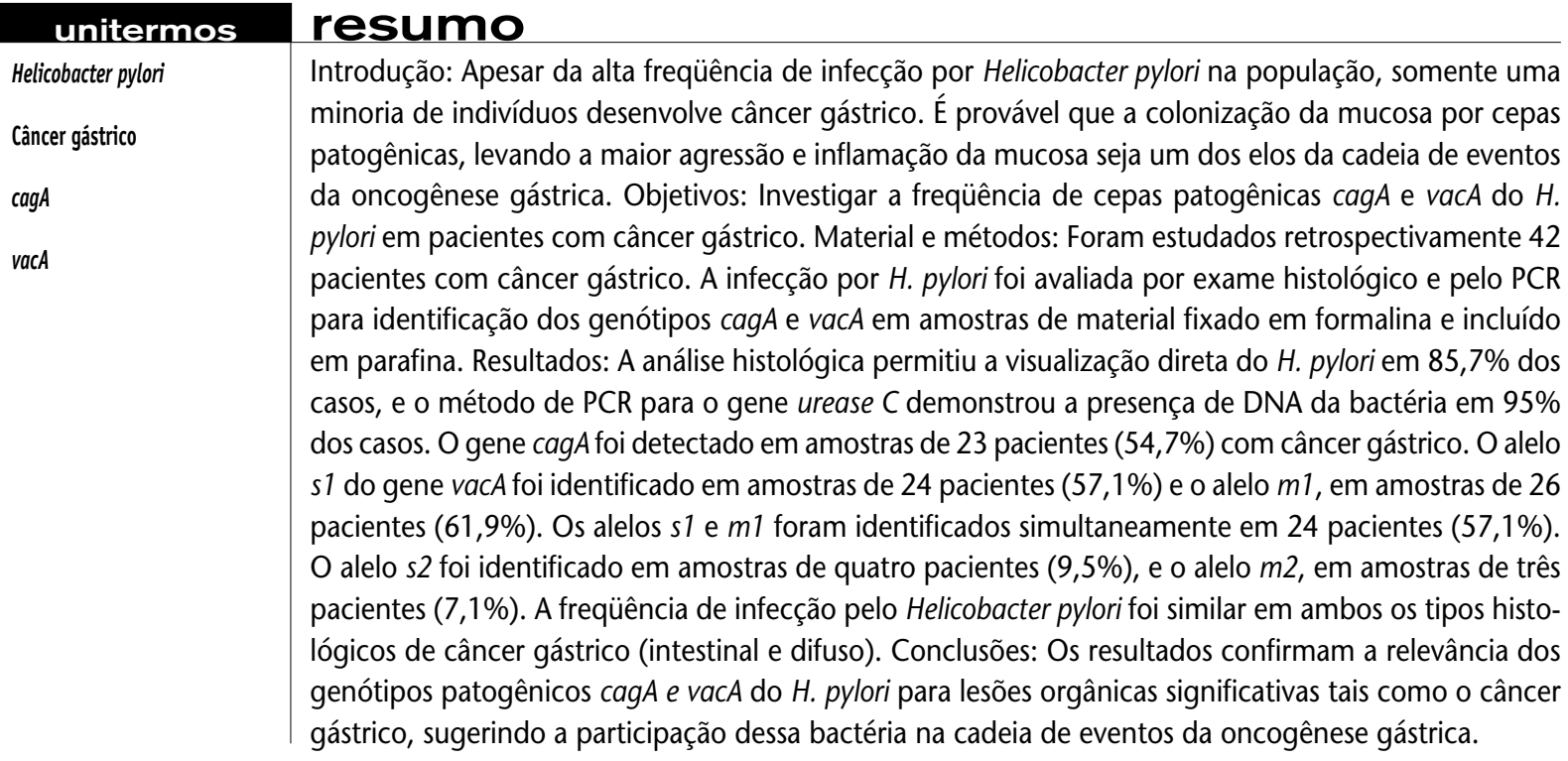

abstract

Background: The rates of Helicobacter pylori infection are very high worldwide, but only a minority of infected patients develop gastric carcinoma. This might be related, among several factors, to the colonization of the human stomach by pathogenic Helicobacter pylori strains. Objective: To investigate the distribution of cagA and vacA genotypes of Helicobacter pylori in paraffin-embedded gastric samples from patients with gastric cancer. Material and methods: Paraffin-embedded samples from 42 patients with gastric cancer were histologically examined and evaluated by $P C R$ for $\mathrm{H}$. pylori cagA and vacA ( $s$ and $m$ regions) genotypes. Results: Histological analysis allowed direct visualization of $\mathrm{H}$. pylori in $85.7 \%$ of cases and $P C R$ for urease $C$ gene detected $\mathrm{H}$. pylori in $95 \%$ of cases. The presence of cagA gene was detected in 23 (54.7\%) patients with gastric cancer. The s 1 allele from vacA gene was found in samples from 24 (57.1\%) patients and the $m 1$ allele in 26 (61.9\%). The s1 $1 \mathrm{~m} 1$ genotype was detected in 24 (57.1\%) patients with gastric cancer. The s2 allele was found in samples from four patients $(9.5 \%)$ and the $m 2$ allele in three (7.1\%) patients. The distribution of H. pylori genotypes was similar in both intestinal and diffuse types of gastric carcinoma. Conclusion: Our results confirm the relevance of the pathogenic cagA and vacA H. pylori genotypes for significant organic lesions, such as gastric cancer, suggesting a possible role for $\mathrm{H}$. pylori in the pathogenesis of gastric carcinoma. key words

Helicobacter pylori

Gastric cancer

cagA

vacA

1. Mestranda do Programa de Pós-Graduação em Patologia da Faculdade de Medicina de Botucatu/Universidade Estadual Paulista (Unesp).

2. Pesquisadora científica do Laboratório de Biologia Molecular do Hemocentro, Faculdade de Medicina de Botucatu/Unesp.

3. Professor livre-docente do Departamento de Cirurgia e Ortopedia da Faculdade de Medicina de Botucatu/Unesp.

4. Professora titular do Departamento de Patologia da Faculdade de Medicina de Botucatu/Unesp.

Apoio financeiro: Fundação para o Desenvolvimento da UNESP (Fundunesp). 


\section{Introdução}

O câncer gástrico permanece entre os problemas mais sérios de saúde em vários países, incluindo o Brasil(12, 27). O diagnóstico geralmente é feito na fase avançada de progressão da doença, o que dificulta a eficácia dos procedimentos terapêuticos e o prognóstico dos pacientes ${ }^{(5)}$. Torna-se, portanto, relevante a identificação de fatores que possam ser utilizados como biomarcadores de risco para essa doença.

Os fatores etiológicos envolvidos na gênese do câncer gástrico não são inteiramente conhecidos. Estudos epidemiológicos demonstram a importância de fatores ambientais, notadamente alimentares, na patogenia do câncer gástrico ${ }^{(7,11,24)}$. Um novo fator tem sido investigado na oncogênese gástrica: postula-se que a infecção pelo Helicobacter pylori levando à gastrite crônica, atrofia da mucosa e metaplasia intestinal tenha participação na cadeia de eventos da gênese do câncer gástrico ${ }^{(13,18,22)}$. A Organização Mundial de Saúde classificou o H. pylori como agente carcinogênico do grupo I para a ocorrência de neoplasias gástricas ${ }^{(13)}$. O H. pylori está presente em grande parcela da população mundial. No entanto, ínfimo número de pessoas desenvolve câncer gástrico. $\mathrm{O}$ risco é de cerca de $1 \%$ nos indivíduos infectados ${ }^{(11)}$. Assim, as diferentes cepas da bactéria com padrões de virulência distintos devem atuar no hospedeiro, levando a diferentes graus de inflamação da mucosa gástrica. A virulência do $\mathrm{H}$. pylori tem sido relacionada a diferentes fatores, incluindo a produção de urease, a presença de flagelos e a citotoxina vacuolizante $^{(14,21)}$.

Em estudos recentes observamos que pacientes com infecção por Helicobacter pylori apresentaram danos no DNA das células epiteliais da mucosa gástrica, que se correlacionaram com a intensidade da resposta inflamatória na mucosa e com os genótipos patogênicos cagA e vacA do $H$. pylori ${ }^{i 15,16)}$. Esses resultados abrem a perspectiva de se investigar a possível correlação entre os diferentes genótipos da bactéria e as características clinicopatológicas do câncer gástrico.

A presente investigação visa avaliar a freqüência de infecção por Helicobacter pylori em amostras de mucosa gástrica, de material fixado em formalina e incluído em parafina, procedentes de pacientes com câncer gástrico e caracterizar, pela reação da polimerase em cadeia (PCR) com oligonucleotídeos específicos, os genótipos patogênicos cagA e vacA da bactéria.

\section{Material e métodos}

\section{Casuística}

Quarenta e dois casos de câncer gástrico diagnosticados e arquivados no Departamento de Patologia da Faculdade de Medicina de Botucatu, da Universidade Estadual Paulista (Unesp), no período de 1998 a 2004, foram analisados neste estudo. As informações clínicas foram pesquisadas nos prontuários dos pacientes.

\section{Seleção das amostras e estudo histopatológico}

Amostras de tumor e respectivo tecido normal foram obtidas a partir de tecidos fixados em formalina e incluídos em parafina. Cortes histológicos de $5 \mu \mathrm{m}$ corados por hematoxilina-eosina foram submetidos a exame histopatológico para caracterização de tipo histológico, contaminação com tecido normal e estadiamento das neoplasias. Os tumores foram classificados em intestinal ou difuso, de acordo com a classificação de Lauren ${ }^{(17)}$. Tumores com expressão morfológica combinada, intestinal e difusa, foram designados mistos. A gastrite foi classificada de acordo com a classificação de Sydney ${ }^{(9)}$. A pesquisa de Helicobacter pylori foi feita pelo exame histológico, na mucosa gástrica adjacente à neoplasia, em cortes corados pelo método de Giemsa. A caracterização dos genótipos do Helicobacter pylori foi feita por PCR. O estudo foi analisado e aprovado pelo Comitê de Ética e Pesquisa da Faculdade de Medicina de Botucatu/Unesp.

\section{Detecção dos genótipos do H. pylori por PCR}

Amostras do tumor e da mucosa adjacente à neoplasia foram obtidas de cortes histológicos do material fixado em formalina, incluído em parafina. A extração do DNA genômico dos tumores e respectivos tecidos normais de cada paciente foi feita por tratamento com proteinase $\mathrm{K} \mathrm{e}$ pelo Kit Wizard (Promega).

A integridade e a qualidade das amostras extraídas foram verificadas por $\mathrm{PCR}$ com oligonucleotídeos iniciadores para o gene constitutivo GAPDH (gliceraldeído 3-fosfato). Foram investigadas seqüências específicas para o gene urease $C$, gene espécie-específico presente em todas as amostras de $H$. pylori, que codifica a enzima urease, bem como para o gene de virulência cagA do $H$. pylori. A composição de bases dos oligonucleotídeos iniciadores, o tamanho das seqüências, as referências e a temperatura de anelamento utilizadas são apresentados na Tabela 1. 


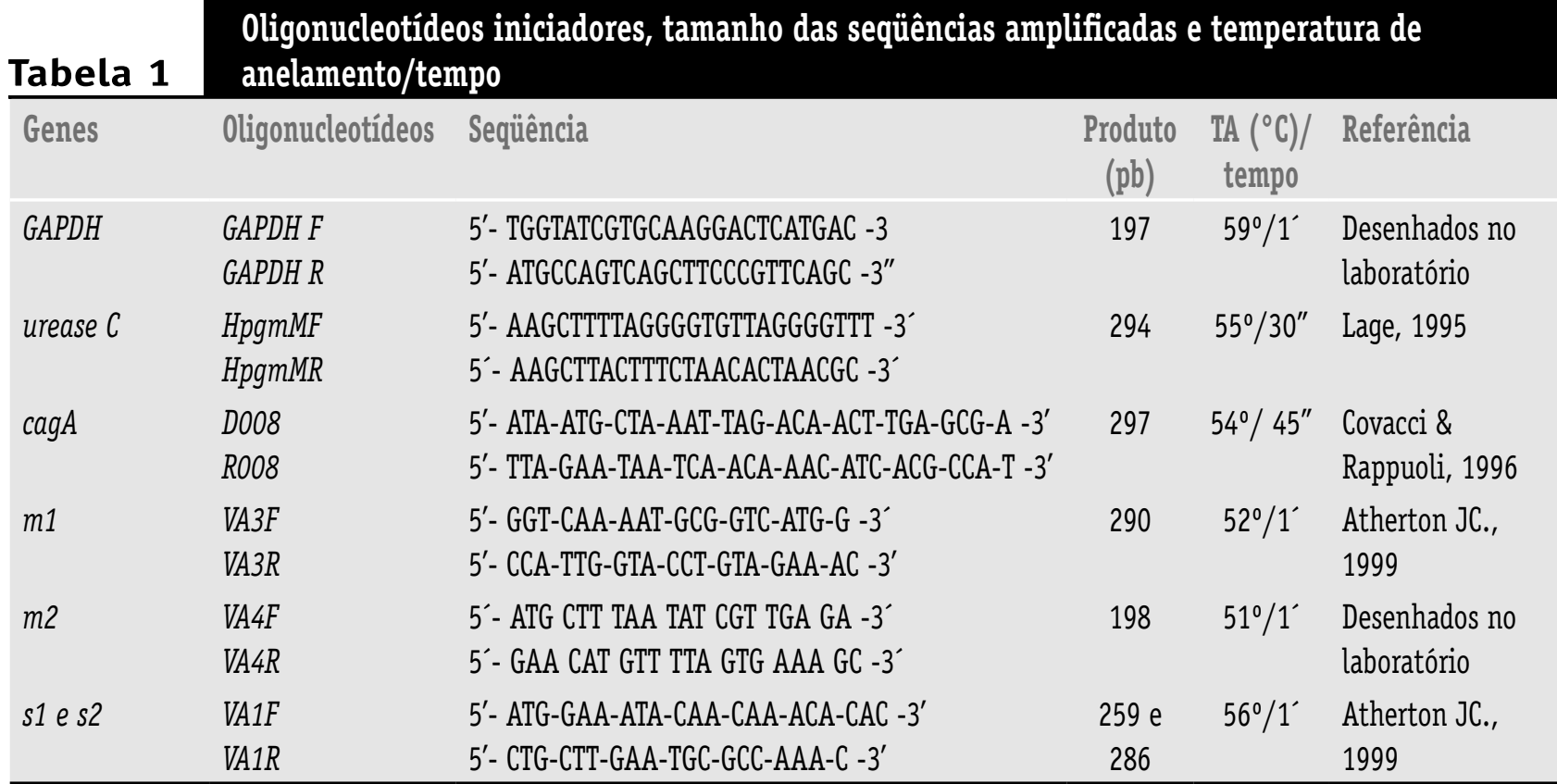

A mistura de reação de PCR para detecção do gene GAPDH constou de: tampão de reação $10 \times[200 \mathrm{mM}$ Tris- $\mathrm{HCl}, 500 \mathrm{mM} \mathrm{KCl}(\mathrm{pH} 8.4)] ; 1,5 \mathrm{mM} \mathrm{MgCl} ; 0,4 \mathrm{mM}$ de cada dNTP(10mM); $1 \mu$ de Platinum Taq DNA Recombinante $(5 \mu \mathrm{l} / \mu \mathrm{l})$ (Invitrogen Life Technologies); 5 pmoles de cada oligonucleotídeo (sense e antisense); $1 \mu$ l de DNA molde (concentrado) e água q.s.p. $25 \mu$ l. Para a detecção dos genes urease $C$ e cagA foram utilizados: tampão de reação $10 x$ [200mM Tris- $\mathrm{HCl}, 500 \mathrm{mM} \mathrm{KCl}(\mathrm{pH} 8.4)]$; $3 \mathrm{mM} \mathrm{MgCl}(50 \mathrm{mM}) ; 0,2 \mathrm{mM}$ de cada dNTP( $10 \mathrm{mM}), 1 \mu \mathrm{l}$ de Platinum Taq DNA Platinum $(5 \mu \mathrm{l} / \mu \mathrm{l})$ (Invitrogen Life Technologies); 5 pmoles de cada oligonucleotídeo (sense e antisense); $1 \mu \mathrm{l}$ de DNA molde (concentrado) e água q.s.p. $25 \mu \mathrm{l}$. A eletroforese do DNA amplificado foi realizada em gel de poliacrilamida $6 \%$ e corada pelo nitrato de prata.

Para a amplificação do gene vacA e de seus alelos $s 1 / s 2$ e $\mathrm{m} 1 / \mathrm{m} 2$ foram utilizados $1 \mu \mathrm{l}$ de DNA e oligonucleotídeos específicos para cada região (Tabela 1). Na reação de PCR para os alelos $m 1$ e $m 2$ utilizou-se solução contendo: $1.5 \mu l$ de AmpliTaq Gold (5 $\mathrm{\mu l} / \mathrm{ml}$ Applied Biosystems); tampão 10x para PCR [100mMTris-HCl pH 8.3, 500mM KCl, 3mM de $\mathrm{MgCl}_{2} 0.01 \%$ de gelatina](Applied Biosystems); $0,4 \mathrm{mM}$ de oligonucleotídeos iniciadores sense e antisense; $1 \mu \mathrm{l}$ de DNA molde (concentrado); $0,4 \mathrm{mM}$ de dNTPs e água q.s.p. $25 \mathrm{ml}$. Na reação de PCR para a região $s$ do gene vacA utilizou-se solução contendo: $1 \mu$ l de Accu Primer (Invitrogen Life Technologies); tampão 10x para PCR [100mM Tris- $\mathrm{HCl}$ pH 8.3, $500 \mathrm{mM} \mathrm{KCl}, 0,4 \mathrm{mM}$ de dNTPs]; $3 \mathrm{mM}$ de $\mathrm{MgCl}_{2} ; 0,4 \mathrm{mM}$ de oligonucleotídeos iniciadores sense e antisense; $1 \mu \mathrm{l}$ de
DNA molde (concentrado) e água q.s.p. $25 \mathrm{ml}$. As reações foram realizadas em termociclador do tipo MJ Research, (Waretown, MA, USA). A visualização do produto de PCR foi realizada em gel de poliacrilamida $6 \%$ não-desnaturante, corado com nitrato de prata ${ }^{(26)}$. Como controles positivos e negativos para vacA (s $1 / \mathrm{s} 2$ e $\mathrm{m} 1 / \mathrm{m} 2)$, cagA e urease $C$, foram utilizadas amostras previamente genotipadas como positivas ou negativas e submetidas a seqüenciamento, em seqüenciador automático ABI Prism 377 (Applied Biosystems) e comparadas às seqüências depositadas nos bancos de dados genômicos públicos.

\section{Resultados}

Os atributos demográficos e anatomopatológicos são apresentados na Tabela 2. A idade dos pacientes variou de 27 a 78 anos, sendo a média 62,2 anos. Vinte e quatro pacientes eram do sexo masculino (58\%) e 18, do sexo feminino (42\%). O exame anatomopatológico demonstrou que o tumor estava localizado no antro gástrico em 26 casos (61,9\%). Tumores em localização proximal, situados no corpo ou na cárdia foram observados em 16 casos (38,1\%). O tipo histológico mais freqüente foi o adenocarcinoma intestinal, identificado em 34 casos (80,9\%). O tipo difuso foi observado em seis casos (14,2\%). Neoplasias com fenótipo morfológico misto, constituídas por áreas de padrão intestinal e áreas de padrão difuso foram identificadas em dois casos $(4,7 \%)$.

A análise histológica da mucosa gástrica adjacente às neoplasias demonstrou em todos os casos a presença de 
infiltrado inflamatório linfoplasmocitário com neutrófilos, cuja intensidade variou de leve a grave, no cório da mucosa. Metaplasia intestinal foi observada em 22 casos (52,3\%). A pesquisa de Helicobacter pylori pelo método de Giemsa foi positiva em 36 casos (85,7\%). A freqüência de infecção por Helicobacter pylori foi similar em ambos os tipos histológicos de câncer gástrico (intestinal e difuso).

\section{Distribuição dos genótipos do $H$. pylori por PCR}

A Tabela 3 demonstra a distribuição dos genes urease C, cagA e de genótipos do vacA em amostras da mucosa gástrica de 42 pacientes com câncer gástrico.

O gene urease $C$, espécie-específico para o $H$. pylori, foi identificado em amostras obtidas de 40 pacientes (95\%) com câncer gástrico. O gene cagA foi detectado em amostras de 23 pacientes $(54,7 \%)$ com câncer gástrico. $O$ alelo $s 1$ do gene vacA foi identificado em amostras de 24 pacientes $(57,1 \%)$, e o alelo $s 2$ foi identificado em amostras obtidas de seis pacientes (14,2\%) com câncer gástrico. Três amostras apresentaram simultaneamente os alelos $\mathrm{s} 1 / \mathrm{s} 2$. O alelo $m 1$ foi detectado em amostras de 26 pacientes (61,9\%). O alelo $m 2$ foi encontrado em três amostras (7,1\%). Duas amostras apresentaram os dois alelos $m 1 / m 2$. A combinação alélica s1 e $m 1$ foi identificada em 24 pacientes $(57,1 \%)$ com câncer gástrico.

\section{Discussão}

No presente estudo descrevemos a análise de cepas do H. pylori por PCR na mucosa gástrica de 42 pacientes com câncer gástrico. A investigação foi retrospectiva, em amostras de tecido fixado em formalina e incluído em parafina. Tal abordagem foi oportuna, porque permitiu detectar a presença de DNA do H. pylori e estimar a possível relação de cepas patogênicas dessa bactéria com parâmetros clinicopatológicos do câncer gástrico.

A detecção do H. pylori foi avaliada por dois métodos: pela análise histológica, que permitiu a visualização direta da bactéria em $85,7 \%$ dos casos e pelo PCR, para o gene urease $C$, que demonstrou a presença de DNA da bactéria em $95 \%$ dos casos. O método de visualização direta ao microscópio é eficiente e de baixo custo, entretanto requer habilidade diagnóstica do analista para identificar a bactéria ${ }^{(10)}$. Já o método de PCR, apesar do custo, apresenta maior sensibilidade, como pode ser documentado por nossos resultados, visto que foi capaz de identificar o genótipo do H. pylori em cinco amostras que haviam sido negativas ao exame histológico.
Atributos demográficos e patológicos dos 42 casos de câncer Tabela 2 gástrico

\begin{tabular}{lll}
\hline Variável & Categoria & $N^{0}$ casos $(\%)$ \\
Gênero & Masculino & $24(57,1)$ \\
& Feminino & $18(42,8)$ \\
Local & Antro & $26(61,9)$ \\
& Corpo & $16(38,1)$ \\
Tipo histológico & Intestinal & $34(80,9)$ \\
& Difuso & $6(14,2)$ \\
& Misto & $2(4,7)$ \\
Nível de invasão & Mucosa/submucosa & $13(31)$ \\
& Serosa/muscular & $29(69)$ \\
Metástases/ & Ausentes & $15(35,7)$ \\
linfonodos & Presentes & $27(64,3)$ \\
\hline
\end{tabular}

Tabela 3
Distribuição dos genes urease C, cag $A$ e de alelos do vacA em amostras da mucosa gástrica de 42

\begin{tabular}{cc} 
Tabela 3 & pacientes com câncer gástrico \\
\hline Genótipo & Pacientes $(\%)$ \\
urease C & $40(95)$ \\
cagA & $23(54,7)$ \\
vacA $s 1$ & $24(57,1)$ \\
vacA $s 2$ & $4(9,5)$ \\
vacA $m 1$ & $26(61,9)$ \\
vacA $m 2$ & $3(7,1)$ \\
vacA s1 $m 1$ & $24(57,1)$ \\
\hline
\end{tabular}

O gene $\operatorname{cagA}$, que é marcador da ilha de patogenicidade cagPAl, codificadora de componentes do sistema de secreção da bactéria ${ }^{(4,19)}$ foi identificado em $54,7 \%$ dos casos de câncer gástrico analisados no presente estudo. Esses dados estão de acordo com investigações prévias, que demonstraram que pacientes infectados por cepas de $\mathrm{H}$. pylori que expressam o gene cagA têm maior probabilidade de desenvolver câncer gástrico do que aqueles infectados por cepas que não expressam $\operatorname{cag} A^{(3,20)}$. No Brasil, estudo de casos controle desenvolvido em Belo Horizonte, Minas Gerais, demonstrou que o status cagA tem alto impacto no risco para desenvolvimento de câncer gástrico distal ${ }^{(23)}$.

Os alelos $s 1$ e $m 1$ do gene $v a c A$, que codifica a produção da citotoxina vacuolizante ${ }^{(25,28)}$, foram detectados em 
$57,1 \%$ e $61,9 \%$ dos casos, respectivamente, na presente investigação. A citotoxina vacA é considerada importante fator de virulência, visto que contribui para a produção, pela urease, de alcalóides que podem induzir danos no DNA das células epiteliais ${ }^{(14,25,28)}$. Em estudo recente observamos que a colonização da mucosa gástrica por cepas cagA/vacA s1 $\mathrm{m} 1$ do $\mathrm{H}$. pylori associou-se a resposta inflamatória mais intensa e maiores níveis de danos no DNA das células epiteliais ${ }^{(16)}$. Esses dados referendam a correlação dos genótipos patogênicos cagA e vacA do $H$. pylori com a agressão crônica à mucosa expressa em nível morfológico por infiltrado inflamatório rico em enzimas e radicais livres capazes de lesar as células epiteliais. A reparação inadequada de lesões no DNA das células pode levar a mutações e instabilidade genômica, constituindo a etapa de iniciação do processo de carcinogênese.

Com relação à combinação dos diferentes alelos do Helicobacter pylori, verificamos que cepas cagA $+\operatorname{sim} 1$ foram encontradas em maior número de casos de câncer gástrico. Na literatura observamos que cepas $\operatorname{cag} A+s 1 / m 1$ são mais virulentas ${ }^{(2)}$. Bactérias com o genótipo $m 1$ estão relacionadas com maior liberação de citotoxinas ${ }^{(1)}$. Dessa forma, a presença de cepas cagA $+s 1 / m 1$ pode estar relacionada a maior agressão e inflamação na mucosa, contribuindo para a gênese do câncer gástrico.
Não encontramos diferenças quanto à distribuição dos genótipos cagA e vacA do $H$. pylori em relação ao sexo e à idade dos pacientes, bem como quanto aos tipos histológicos intestinal ou difuso do câncer gástrico. Apesar de a presente casuística ser pequena, nossos resultados estão de acordo com os relatados pelos estudos de Queiroz, que também não observaram correlação dos genótipos da bactéria com atributos demográficos e com parâmetros histopatológicos do câncer gástrico(23).

Em síntese, a presença de infecção por Helicobacter pylori, avaliada em nosso estudo pela análise histológica, permitiu a visualização direta da bactéria em $85,7 \%$ dos casos, e pelo PCR, para o gene urease $C$, demonstrou a presença de DNA da bactéria em 95\% dos casos, sendo a combinação alélica mais freqüente $\operatorname{cag} A+v a c A s 1 / \mathrm{m} 1$. Esses resultados destacam a alta prevalência de infecção por Helicobacter pylori no estômago de pacientes com câncer gástrico atendidos na região de Botucatu, São Paulo, e confirmam a relevância do genótipo cagA $\mathrm{m} 1 / \mathrm{s} 1$ na patogênese do câncer gástrico.

\section{Agradecimentos}

À Fundação para o Desenvolvimento da UNESP (Fundunesp), processo 940/04, pelo auxílio à pesquisa.

\section{Referências}

I.ASHOUR,A.A. et al. Distribution of vacA genotypes in Helicobacter pylori strains isolated from Brazilian adult patients with gastritis, duodenal ulcer or gastric carcinoma. FEMS Imunol Med Microbiol, v. 33, p. I73-78, 2002.

2. ATHERTON, J.C. The clinical relevance of strain types of Helicobacter pylori. Gut, v. 40, p. 701-03, 1997.

3. BLASER, M.J. et al. Infection with Helicobacter pylori strains possessing cagA is associated with an increased risk of developing adenocarcinoma of the stomach. Cancer Res, v. 55, p. 2 III-15, 1995.

4. CENSINI, S. et al. Cag, a pathogenicity island of Helicobacter pylori, encodes type I-specific and disease-associated virulence factors. Proc Nat Acad Sci, v. 93, p. 14648-53, 1996.

5. CHEN-WUN, W.; CHIN-WEN, C.; WEN-CHANG, L. Gastric cancer: prognostic and diagnostic advance. Exp Rev Mol Med, v. 21 , p. I 10-5, 2002.

6. CLAYTON, C.L. et al. Sensitive detection of Helicobacter pylori by using polymerase chain reaction. J Clin Microbiol, v. 30, p. 192-200, 1992.

7. CORREA P. Human gastric carcinogenesis: a multistep and multifactorial process - First American Cancer Society Award Lecture on cancer epidemiology and prevention. Cancer Res, v. 52, p. 6735-40, 1992.
8. D'AQUINO, A. et al. Prevalência de infecção por Helicobacter pylori em pacientes com câncer gástrico. J Bras Patol, v. 39 , p. 130, 2003.

9. DIXON, M.F. et al. Classification and grading of gastritis: the updated Sydney System - International Workshop on the Histopathology of Gastritis, Houston 1994. Am J Surg Pathol, v. 20, p. | |6|-81, 1994.

I 0.FALLONE, C.A.; MITCHELL,A.;PATERSON,W.G. Determination of the test performance of less costly methods of Helicobacter pylori detection. Clin Invest Med, v. 18, p. 177-85, 1995.

I I. FORMAN, D. The etiology of gastric cancer. IARC Sci Publ, v. I05, p. 22-32, I991.

I2. FUCHS, C.S.; MAYER, R.J. Gastric carcinoma. N Engl J Med, v. 333, p. 32-4I, 1995.

13. IARC Working Group on the Evaluation of Carcinogenic Risks to Humans. Schistosomes, liver flukes and Helicobacter pylori. IARC Monogr Eval Carcinog Risks Hum, v. 6I, p. I-24I, 1994.

14. LADEIRA, M.S.P. et al. Biopatologia do Helicobacter pylori.J Bras Patol, v. 39, p. 275-82, 2003.

15. LADEIRA, M.S.P. et al. DNA damage in patients infected by Helicobacter pylori. Cancer Epidemiol Biomarkers Prev, v. I3, p. 63I-37, 2004a.

16. LADEIRA, M.S.P. et al. Relationships between $\operatorname{cagA}$, vacA, and 
ice genotypes of Helicobacter pylori and DNA damage in the gastric mucosa. Environ Mol Mutagen, v. 44, p. 91-98, 2004b.

17. LAUREN, P.The two histological main types of gastric carcinoma. Diffuse and so-called intestinal type carcinoma: an attempt at histoclinical classification. Acta Pathol Microbiol Scand, v. 64, p. 31-49, 1965.

18. O'CONNOR, F.; BUCKELEY, M.; O MORAIN, C. Helicobacter pylori: the cancer link. J R Soc Med, v. 86, p. 674-8, 1996.

19. ODENBREIT, S. et al.Translocation of Helicobacter pylori cagA into gastric epithelial cells by type IV secretion. Science, v. 287, p. I497-500, 2000

20. PARSONNET,.. et al. Risk for gastric cancer in people with cagA positive and cagA negative Helicobacter pylori infection. Gut, v. 40, p. 297-30I, 1997

2 I. PEEK Jr, R.M.; BLASER, MJ. Pathophysiology of Helicobacter pylori-induced gastritis and peptic ulcer disease. Am J Med, v. 102, p. 200-5, 1997.

22. PEEK Jr, R.M.; BLASER, M.J. Helicobacter pylori and gastrointestinal tract adenocarcinomas. Nat Rev Cancer, v. 2, p. 28-37, 2002.
23. QUEIROZ, D.M.M. et al. CagA-positive Helicobacter pylori and risk for developing gastric carcinoma in Brazil. Int J Cancer, v. 78, p.135-39, 1998.

24. RODER, D.M.The epidemiology of gastric cancer. Gastric Cancer, v. 5, p. 5-1 I, 2002

25. SALAMA, N. R. et al. Vacuolating cytotoxin of Helicobacter pylori plays a role during colonization in a mouse model of infection. Infect Immun, v. 69, p. 730-6, 200 I.

26. SANGUINETTI, C...; DIAS NETO, E.; SIMPSON, A.J. Rapid silver staining and recovery of PCR products separated on polyacrylamide gels. Biotechniques, v. 17, n. 5, p. 914$21,1994$.

27. SÃO PAULO (Estado). Secretaria da Saúde. Fundação Oncocentro de São Paulo. Mortalidade por câncer no Estado de São Paulo: tendência temporal e características regionais, 1987 a 2003. Cadernos FOSP, v. 4, 2005.

28. SZABO, I et al. Formation of anion-selective channels in the cell plasma membrane by the toxin vacA of Helicobacter pylori is required for its biological activity. EMBO J, v. $18, \mathrm{p}$ 55|7-27, 1999. 